Preliminary measurements of solubilities and of $p \mathrm{~K}$ 's might discriminate between substances worth testing and those which would be useless.

Prof. R. Robinson asked why it is that plants so often contain alkaloids with marked actions on animal tissues. This may be explained by some theory of the biological history of the animals and plants which have developed together, or it may be due to the fact that the alkaloids are probably degradation products of proteins, since their structure can usually be derived formally from the naturally occurring amino acids.

\section{Magnetic Properties of the Nickel-Iron Alloys}

$I^{\mathrm{N}}$ a pamphlet issued by the Bureau of Information on Nickel of the Mond Nickel Co., Ltd., Millbank, S.W.1, an account is given of nickel-iron alloys and their characteristics which will be of special value to electrical engineers and manufacturers.

The magnetic properties present very striking contrasts. The permeability of pure iron, for example, is gradually reduced by additions of nickel exceeding ten per cent, until in the region of 30 per cent the alloys are completely non-magnetic. Further additions of nickel give a range of alloys containing 35-85 per cent of nickel, which have a very high magnetic permeability and are in fact the softest materials magnetically that are commercially avail. able. New alloys have now been developed by adding substantial proportions of nickel and aluminium, which are very hard and form permanent magnets of great strength. The 25 per cent nickel steel is characterized by an extremely high ductility and is corrosion resisting. It is practically nonmagnetic and is used extensively in electrical engineering.

The group of iron alloys having 35-80 per cent of nickel, on account of their high permeability, are of great commercial importance. In 1921 the Western Electric Co. of America took out a patent for an alloy consisting of 78.5 per cent nickel and $21 \cdot 5$ per cent iron, all impurities being kept as low as possible. The heat treatment necessary consisted in heating the alloy to $900^{\circ} \mathrm{C}$. and then cooling at a definite rate. The alloys patented by this company are given the general name of 'permalloy'. Since then, patents have been taken out for other nickel-iron alloys, containing small proportions of other elements. 'Mumetal', patented by the Telegraph Construction and Maintenance Co., Ltd., London, is one of these. It contains 6 per cent of copper, which facilitates heat treatment and stabilizes the alloy.

The first use to which the high permeability alloys were put was for the 'loading' of submarine cables. In accordance with Heaviside's theory, this would prevent distortion of the signals and also their attenuation. Simultaneously with the development of the loaded submarine cable, continuous attention was given to long-distance land line cables, and nickeliron devices were found very helpful. Afterwards, in order to save space, it was found advantageous to employ the magnetic alloy in the form of dust or powder. Various chemical and physical methods are used to produce the alloy in this form. A drawback is that the powder has very low permeability, but the energy losses in it are much smaller.
In the year 1930, news first came from Japan of the discovery of a new series of permanent magnet alloys in which the principal alloying elements were nickel and aluminium. Since their introduction, these new magnet steels have been intensively studied, and they are now superseding the cobalt and other steels previously used for these applications. These alloys offer the maximum magnetic energy per unit volume yet available to manufacturers. One of the most important applications of the new magnets is for radio loud speakers. In the manufacture of small motors, magnetos and other small-sized dynamo electric equipment, the nickel alloy magnets are found very efficient and adaptable. They are used in the magnetic detectors used in 'automatic' traffic signalling.

On the theoretical side, our knowledge of magnetic alloys is far from complete. When we have a better knowledge of how heat treatment affects them, still more useful alloys may become available.

\section{Educational Topics and Events}

Cambridge.-The Vice-Chancellor has received a letter from Sir Harry McGowan, chairman of Imperial Chemical Industries, Ltd., stating that it is not proposed to continue to support financially the work on molecular rays carried out since 1929 by Mr. R. G. J. Fraser, who has now been appointed to the research staff of I.C.I. (Alkali) Ltd. The ap. paratus and equipment installed, at a cost of about $£ 2,500$, is being offered to the University for the use of the Departments of Chemistry and Physics, and Sir Harry hopes that it will continue to be used for research on molecular rays.

The Managers of the Benn W. Levy Fund have appointed K. P. Harrison, of King's College, to the studentship in biochemistry.

J. H. Gaddum (Trinity College), W. B. R. King (Magdalene College) and Dr. O. M. B. Bulman (Sidney Sussex College) have been approved for the degree of Sc.D.

The Governing Body of Emmanuel College invites applications for a research studentship which will be awarded in July 1937. Preference will be given to candidates who have already com. pleted one but not more than two years of research. The studentship, which must be held at Emmanuel College, and has a maximum annual value of $£ 150$, is awarded and normally held for two years, but may be renewed for a third. Further information can be obtained from the Master of the College.

LoNDON.-The title of professor of pathology of mental disease in the University has been conferred on F. L. Golla, in respect of the post held by him at the Maudsley Hospital ; that of professor of psychiatry in the University on Dr. Edward Mapother, in respect of the post held by him at the Maudsley Hospital, and that of reader in mathematics in the University on Dr. L. S. Bosanquet, in respect of the post held by him at University College.

The following doctorates have been conferred: D.Sc. in botany on H. Chaudhuri (Imperial College-Royal College of Science); D.Sc. in horticulture on R. G. Hatton (East Malling Research Station); D.Se. in physies on F. C. Chalklin (King's College). 